\title{
Reforma electoral 2020 y sistemas electorales nacionales y locales: igualdad, proporcionalidad y paridad
}

\section{Electoral reform 2020 and national and local electoral systems: equality, proportionality and parity}

Richard Ortiz Ortiz

Recepción: 18-05-2020

Resumen:

Aceptación: 04-07-2020

En febrero de 2020 fue publicada la última reforma electoral que modifica elementos centrales de los sistemas electorales de los órganos de elección popular a nivel nacional y local. Este trabajo tiene como objetivo evaluar dicha reforma bajo los parámetros constitucionales de igualdad del voto, proporcionalidad y paridad en las instituciones representativas. La tesis que guía el análisis es que la reforma no resuelve los problemas de representación en Ecuador, pero introduce medidas eficaces para mejorar la participación de las mujeres en la política nacional y local.

Palabras claves: reforma electoral, sistemas electorales, igualdad, proporcionalidad, paridad.

Abstract:

On February 2020, the last electoral reform, which modifies the main elements of the electoral systems of the popular election locally and nationally was published. The main objective of this work is assessing the reform under the constitutional parameters toward equality of the vote, proportionality and parity in the representative institutions. The thesis that guides this analysis is that this reform does not solve the representation issues in Ecuador but provides effective measures to improve women's participation in national and local politics.

Key words: electoral reform, electoral systems, equality, proportionality, parity. 


\section{Introducción}

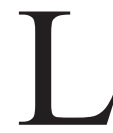

a última reforma a la Ley Orgánica Electoral y Organizaciones Políticas (LOEOP) fue promulgada el 3 de febrero de 2020 en el Registro Oficial. Este estudio se dedica exclusivamente a evaluar aquellas normas de la reforma que afecta a los sistemas electorales nacionales y locales y su relación con los principios constitucionales de igualdad, proporcionalidad y paridad, con sus respectivas consecuencias en la representación política. La evaluación se lleva a cabo solo sobre los efectos mecánicos inmediatos de la reforma (Duverger, 2001, pp. 38-47) ${ }^{1}$. La tesis principal de este trabajo es que, las últimas reformas al sistema electoral no alcanzan a solucionar los problemas principales de la representación política en Ecuador, aunque sí introducen modificaciones relevantes que favorecen la paridad de género en los órganos de elección popular a nivel nacional y subnacional.

Ya que la Constitución de la República (CR) de 2008 prevé un sistema de gobierno presidencial, tanto el presidente de la República (art. 143 CR), como los miembros de la Asamblea Nacional (art. 118 CR) son electos popularmente. Ecuador, además, es un Estado unitario que se gobierna de manera descentralizada (art. 1.1 CR). Por ende, el territorio está organizado en distintos gobiernos autónomos descentralizados (GAD), que son electos también por voluntad popular (arts. 251-255 CR). Asimismo, después de la reforma constitucional de febrero de 2018, el Consejo de Participación Ciudadana y Control Social (CPCCS) también es electo con el voto de los ciudadanos (art. 207.3 CR). En consecuencia, en este trabajo se describirán, primero, las características de todos los sistemas electorales a nivel nacional y local, según la reforma de 2020, antes de proceder a su evaluación.

Adicionalmente, el art. 116 de la Constitución ordena que para "las elecciones pluripersonales, la ley establecerá un sistema electoral conforme a los principios de proporcionalidad, igualdad del voto, equidad, paridad y alternabilidad entre mujeres y hombres.” El art. 65 de la Norma Suprema refuerza la participación paritaria de las mujeres. Por tanto, el objetivo de

1 La evaluación empírica de la reforma de 2020 deberá ser hecha después de las elecciones generales de 2021 y las elecciones locales de 2023; pero, hay elementos del sistema electoral que permiten una evaluación previa, independientemente de los resultados electorales. Claro está que, los resultados empíricos serán buenos argumentos para reforzar o rechazar los argumentos expuestos en este trabajo. 
este ensayo es evaluar - preliminarmente- si las reformas de febrero de 2020 contribuyeron a realizar los principios constitucionales en los diversos sistemas electorales a nivel nacional y subnacional.

Con el fin propuesto se procede de la siguiente manera: (1) se define brevemente qué se entiende por sistema electoral y se enumeran sus componentes; (2) se describen los nuevos sistemas electorales a nivel nacional y local, conforme con la reforma de 2020; (3) se evalúa la reforma de febrero de 2020 bajo los estándares constitucionales de los principios de igualdad, proporcionalidad y paridad; y, (4) se resumen las principales conclusiones de este trabajo.

\section{Sistemas electorales: definición y componentes}

Para el análisis de los sistemas electorales y sus efectos es recomendable partir de una definición estricta de sistema electoral, que comprende el conjunto de reglas que definen el modo según el cual el elector manifiesta, por medio del voto, su preferencia política por un partido o candidato, y la manera en que esos votos se convierten en un cargo público (Nohlen, 2020, p. 373). En este sentido, las normas que regulan el sistema electoral no abarcan todas las reglas electorales que se pueden referir a los procesos electorales, financiamiento electoral, autoridad electoral, justicia electoral y partidos políticos. ${ }^{2}$ Estas reglas solo se limitan a regular los aspectos de la expresión del voto y la transformación de esos votos en un puesto de elección popular nacional o local, unipersonal o pluripersonal.

Los componentes de los sistemas electorales, tanto para elecciones unipersonales y pluripersonales, son básicamente cuatro: (1) forma de candidatura, (2) procedimiento de votación, (3) circunscripción y (4) procedimiento de conversión de votos en el cargo público correspondiente. A continuación, se presentan, primero, los sistemas electorales para los órganos nacionales y, luego, para los gobiernos locales (GAD).

2 Sobre los diversos temas que puede abarcar la regulación electoral, puede consultarse la obra monumental sobre Derecho electoral latinoamericano, editada por Nohlen, Valdés y Zovatto (2019). 


\section{Sistemas electorales nacionales}

Solo hay tres órganos nacionales que son electos popularmente para un periodo de cuatro años: la Asamblea Nacional, el presidente de la República y el CPCCS, cuyas reglas de elección están establecidas en la Constitución (arts. 118, 143 y 207.3), LOEOP (arts. 119, 120, 150, 151, 160, 161 y 164) y la Ley Orgánica del Consejo de Participación Ciudadana y Control Social (LOCPCCS, arts. 32-33).

\subsection{Sistema electoral para la Asamblea Nacional}

Las candidaturas para asambleístas, desde la reforma de febrero de 2020 a la LOEOP, se presentan en listas cerradas y bloqueadas. ${ }^{3}$ Así, el art. 120 de la ley manda: "En las elecciones para representantes a la Asamblea Nacional [...] el voto será en lista[s] cerradas y bloqueadas." Por mandato constitucional (arts. 108 y 116) y legal (arts. 3, 99 y 160 LOEOP), las candidaturas se establecerán mediante procesos democráticos internos o elecciones primarias, y las listas se estructurarán con estricta paridad, alternabilidad y secuencialidad entre mujeres y hombres. Además, la reforma de febrero de 2020 exige que las listas estén encabezadas por mujeres en un $50 \%$ y se debe garantizar una cuota mínima del $25 \%$ para los jóvenes entre 18 y 29 años, según las reglas del art. 99. ${ }^{4}$ El mandato de encabezamiento paritario se aplicará progresivamente: $2021,15 \%$ y $2025,50 \%{ }^{5}$

La forma de votación en las listas de asambleístas era por personas hasta antes de la reforma de febrero de 2020. Ahora, el voto es por lista y único. Al respecto, el art. 160 LOEOP ordena: "El elector indicará su preferencia por una sola lista según las dignidades que correspondan."

\footnotetext{
3 Antes de la reforma, la lista era abierta.

4 Véase la Disposición General Décima, añadida por la reforma de febrero de 2020.

5 Véase la Disposición Transitoria Tercera, añadida por la reforma de febrero de 2020.
} 
Tabla 1: Circunscripciones electorales para la Asamblea Nacional

\begin{tabular}{|c|c|c|c|c|}
\hline Tamaño & Cantidad & Circunscripciones & $\begin{array}{c}\text { Escaños } \\
\text { totales }\end{array}$ & \% escaños \\
\hline 15 & 1 & Única (nacional ampliada) & 15 & 10,9 \\
\hline 6 & 1 & Los Ríos & 6 & 4,4 \\
\hline 5 & 8 & $\begin{array}{c}\text { Azuay, El Oro, Manabí-C2, Qui- } \\
\text { to-C2, Guayas-C1, Guayas-C2, } \\
\text { Guayas-C3 y Guayas-C4 }\end{array}$ & 40 & 29,2 \\
\hline 4 & 10 & $\begin{array}{c}\text { Cotopaxi, Chimborazo, } \\
\text { Esmeraldas, Imbabura, Loja, } \\
\text { Tungurahua, Santo Domingo, } \\
\text { Quito-C1, Quito-C3, y Mana- } \\
\text { bí-C1 }\end{array}$ & 40 & 29,2 \\
\hline 3 & 6 & $\begin{array}{c}\text { Bolívar, Cañar, Carchi, Sucum- } \\
\text { bíos, Santa Elena, y Pichincha }\end{array}$ & 18 & 13,1 \\
\hline 2 & 9 & $\begin{array}{c}\text { Morona Santiago, Napo, } \\
\text { Pastaza, Zamora Chinchipe, } \\
\text { Galápagos, Orellana, Exterior-1, } \\
\text { Exterior-2 y Exterior-3 }\end{array}$ & 18 & 13,1 \\
\hline $\begin{array}{l}\text { Prome- } \\
\text { dio 3,9 }\end{array}$ & Total 35 & $\begin{array}{c}\text { 1 única, 22 provinciales, 6 sub- } \\
\text { provinciales, 3 subdistritales y } \\
\text { 3 del exterior }\end{array}$ & Total 137 & Total 100 \\
\hline
\end{tabular}

Fuente: tomado de Ortiz, 2016, p. 14.

En cuanto a las circunscripciones, en el sistema electoral legislativo ecuatoriano hay que considerar tanto su tipo como su tamaño, para entender cómo se estructura la representación política territorialmente y el grado de proporcionalidad del sistema. El art. 150 LOEOP establece siete tipos posibles de circunscripciones para las elecciones parlamentarias en Ecuador. Pero, en las elecciones legislativas de 2013 y 2017 solo hubo cinco tipos de circunscripciones: única (o nacional ampliada), provincial, subprovincial, subdistrital y especial del exterior; puesto que, hasta la fecha, no se ha constituido ninguna región en los términos que establece la Constitución en sus arts. 144-146; tampoco hubo circunscripciones distritales, pues el único distrito metropolitano tuvo que subdividirse. Además, el citado art. 150 ordena subdividir las circunscripciones mayores a siete escaños, lo que reduce considerablemente su magnitud. 
El tamaño de la circunscripción es decisivo para los efectos proporcionales de un sistema electoral: mientras más pequeña es la circunscripción menos proporcional será la relación votos-escaños (Lijphart, 1995, p. 44). La Tabla 1 resume las 35 circunscripciones en las que son electos los 137 miembros de la Asamblea Nacional. Solo hay una circunscripción grande, la única (nacional ampliada); una mediana, Los Ríos; y, 33 pequeñas. El promedio global es de 3,9 escaños por circunscripción. Las circunscripciones pequeñas constituyen el $94,3 \%$ del total $y$, con distritos de esa magnitud es casi imposible hacer un reparto justo de escaños en relación con la fuerza electoral de cada organización política (Lijphart, 2000, p. 147149).

El procedimiento de conversión de votos en escaños es el mecanismo mediante el cual, después del escrutinio de votos, se adjudican los puestos parlamentarios a cada partido. Es importante distinguir entre la fórmula de decisión y el método de cálculo para la adjudicación de puestos en el parlamento. La fórmula resume el criterio que decide quién es el ganador o perdedor de una elección, y puede ser mayoritaria o proporcional. Para la elección de miembros de la Asamblea Nacional, la adjudicación de escaños se hace mediante una fórmula proporcional y el cómputo de las proporciones necesarias para acceder a un escaño, mediante el método Webster, que emplea divisores impares (art. 164 LOEOP). 


\section{Tabla 2: Sistema electoral para la Asamblea Nacional}

\begin{tabular}{|c|c|c|c|c|c|}
\hline \multirow{2}{*}{ Candidatura } & \multirow{2}{*}{$\begin{array}{l}\text { Proced. } \\
\text { votación }\end{array}$} & \multicolumn{2}{|c|}{ Circunscripción } & \multirow{2}{*}{$\begin{array}{l}\text { Fórmula de } \\
\text { decisión }\end{array}$} & \multirow{2}{*}{$\begin{array}{l}\text { Método de } \\
\text { Adjudicación }\end{array}$} \\
\hline & & Tipo & Tamaño & & \\
\hline $\begin{array}{c}\text { - Lista } \\
\text { cerrada y } \\
\text { bloqueada } \\
\text { - Secuencial } \\
\text { y alternada } \\
\text { entre mujeres } \\
\text { y hombres. } \\
\text { - } 50 \% \\
\text { encabezadas } \\
\text { por mujeres. } \\
\text { - } 25 \% \text { de } \\
\text { jóvenes. }\end{array}$ & $\begin{array}{l}\text { Voto único } \\
\text { por lista }\end{array}$ & $\begin{array}{c}\text { - Nacional (1) } \\
\text { - Provincial } \\
(22) \\
\text { Subprovincial } \\
\text { (6) } \\
\text { - Subdistrital } \\
\text { (3) } \\
\text { - Del exterior } \\
\text { (3) }\end{array}$ & $\begin{array}{c}\text { - } 1 \text { grande } \\
\text { (nacional) } \\
-1 \text { mediana } \\
\text { (Los Ríos) } \\
-33 \\
\text { pequeñas. } \\
\text { (promedio } \\
\text { 3,9 escaños) }\end{array}$ & $\begin{array}{l}\text { Propor- } \\
\text { cional. }\end{array}$ & $\begin{array}{c}\text { Webster } \\
\text { (divisores } \\
\text { impares: } 1,3 \text {, } \\
5,7 \ldots) .\end{array}$ \\
\hline
\end{tabular}

Nota: a La aplicación será progresiva: 2021, 15\% y 2025, 50\%.

Fuente: Constitución 2008; LOEOP 2009, ref. 2020.

Finalmente, la tabla 2 resume los distintos elementos del sistema electoral para la elección de los 137 miembros de la Asamblea Nacional, después de la reforma electoral de 2020.

\subsection{Sistema electoral para el presidente de la República}

Como resume la tabla 3, las candidaturas para presidente y vicepresidente de la República se presentan en binomio en la misma papeleta (art. 143 CR; art. 161 LOEOP). La reforma de 2020 exige que el binomio sea estrictamente paritario; es decir, si la candidata a la presidencia es mujer, el candidato a la vicepresidencia deberá ser hombre, y viceversa; pero está regla se empezará a aplicar desde las elecciones generales de 2025. ${ }^{6}$ El elector tiene un solo voto para seleccionar a los candidatos de su preferencia.

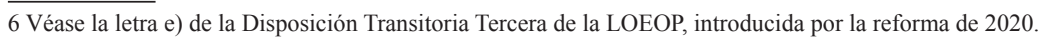


Tabla 3: Sistema electoral para el presidente de la República

\begin{tabular}{|c|c|c|c|}
\hline Candidatura & $\begin{array}{c}\text { Procedimiento de } \\
\text { votación }\end{array}$ & Circunscripción & $\begin{array}{c}\text { Fórmula de deci- } \\
\text { sión }\end{array}$ \\
\hline $\begin{array}{c}\text { Unipersonal } \\
\text { (binomio paritario a) }\end{array}$ & $\begin{array}{c}\text { Voto único } \\
\text { (por binomio) }\end{array}$ & $\begin{array}{c}\text { Única } \\
\text { (nacional más las } \\
\text { tres del exterior) }\end{array}$ & $\begin{array}{l}\text { Fórmula de decisión: } \\
\text { mayoría } \\
\text { Tipo de mayoría: } \\
\text { 1. Relativa califi- } \\
\text { cada ( } 40 \% \text { con una } \\
\text { diferencia de } 10 \\
\text { puntos); o, } \\
\text { 2. Mayoría absoluta. } \\
\text { Si no se cumple } \\
\text { ninguna de estas } \\
\text { condiciones, habrá } \\
\text { una segunda vuelta } \\
\text { con los dos candi- } \\
\text { datos con mayor } \\
\text { votación. }\end{array}$ \\
\hline
\end{tabular}

Nota: a Desde las elecciones de 2025.

Fuente: Constitución 2008; LOEOP 2009, ref. 2020.

Las máximas autoridades de la Función Ejecutiva nacional se eligen en circunscripción única, que incluye el territorio nacional y las tres circunscripciones del exterior (art. 151 LOEOP). Para ser elegido presidente de la República es suficiente, ya sea la mayoría relativa de al menos el 40\% de los votos válidos y una diferencia mayor a 10 puntos porcentuales sobre el segundo candidato mejor votado; o basta con obtener la mayoría absoluta de los votos válidos. Si no ocurre ninguna de estas dos circunstancias, habrá una segunda vuelta (ballotage) entre los dos candidatos mejor votados, en la que el ganador será el que obtenga la mitad más una de las preferencias electorales.

\subsection{Sistema electoral para el CPCCS}

En los arts. 32 y 33 de la LOCPCCS, el Legislador diseña un sistema electoral muy complicado para la elección de los siete miembros del CPCCS (véase tabla 4), e incluso con algunas reglas de dudosa constitucionalidad, 
como la exigencia del título de tercer nivel para ser consejero (art. 20, núm. 6), y la prohibición de las candidaturas de afiliados y adherentes de las organizaciones políticas y de los que hayan ocupado cargos de elección popular durante los últimos cinco años (art. 21, núm. 8; Oyarte, 2019, pp. 1172-1181).

Sobre el tipo de candidatura se establece que se "elaborará una papeleta con tres listas electorales: una de mujeres; una de hombres; $y$, una de pueblos y nacionalidades indígenas, afroecuatorianos o montubios y de ecuatorianos en el exterior, en la que se observará la alternancia de género." (art. 32.1 LOCPCCS). El procedimiento de votación es voto personalizado en cada una de las listas, de la siguiente manera: "Los electores podrán votar por hasta siete candidatos, tres candidatos de la lista de hombres, tres candidatas de la lista de mujeres y un candidato de la lista de los pueblos y nacionalidades indígenas, afroecuatorianos o montubios y de ecuatorianos en el exterior" (art. 32.3 LOCPCCS). Es decir que, en la lista de mujeres, por un lado, y en la de hombres, por otro, el elector cuenta con tres votos (múltiple) para elegir a candidatos de su preferencia (personalizado). Y, en la tercera lista, cuenta con un solo voto para un candidato. 
Tabla 4: Sistema electoral para el CPCCS

\begin{tabular}{|c|c|c|c|c|}
\hline Candidatura & $\begin{array}{c}\text { Procedimiento } \\
\text { de votación }\end{array}$ & $\begin{array}{l}\text { Circunscrip- } \\
\text { ción }\end{array}$ & $\begin{array}{l}\text { Fórmula de } \\
\text { decisión }\end{array}$ & $\begin{array}{l}\text { Tipo de ma- } \\
\text { yoría }\end{array}$ \\
\hline 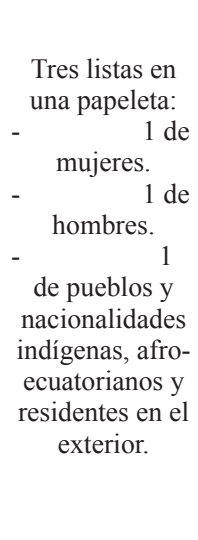 & $\begin{array}{l}\text { Voto personali- } \\
\text { zado: } \\
\text { - } \quad 3 \\
\text { votos (múltiple) } \\
\text { para la lista de } \\
\text { mujeres. } \\
\text { - } \quad 3 \\
\text { votos (múltiple) } \\
\text { para la lista de } \\
\text { hombres. } \\
\text { - } \\
\text { 1 voto (único) } \\
\text { para la tercera } \\
\text { lista. }\end{array}$ & $\begin{array}{c}\text { Única } \\
\text { (nacional más } \\
\text { las tres del } \\
\text { exterior) }\end{array}$ & Mayoría & $\begin{array}{c}\text { - Lista de mu- } \\
\text { jeres: relativa } \\
\text { de las tres can- } \\
\text { didatas mejor } \\
\text { votadas } \\
\text { - Lista de } \\
\text { hombres: } \\
\text { relativa de los } \\
\text { tres candidatos } \\
\text { mejor votados } \\
\text { - Tercera lista: } \\
\text { relativa del } \\
\text { candidato con } \\
\text { más votos } \\
\text { (pero podría } \\
\text { salir electo otro } \\
\text { candidato) }\end{array}$ \\
\hline
\end{tabular}

Nota: a Si en las listas de mujeres y hombres no es electo ningún candidato de los pueblos y nacionalidades indígenas o afroecuatoriano y el primero de la tercera lista tampoco pertenece a estos grupos étnicos; entonces, el ganador podría ser el candidato indígena más votado, independiente de las otras mayorías.

Fuente: LOCPCCS, 2009, ref. 2018.

La circunscripción para la elección de los siete consejeros es la única, que incluye la nacional y las tres del exterior (art. 32.3 LOCPCCS). La forma de convertir los votos en escaños se regula en el art. 33.2 de la misma ley, que consagra la siguiente regla: "se designará a tres hombres, tres mujeres; si dentro de los seis designados o designadas no existiere ninguno perteneciente a pueblos, nacionalidades, indígenas, afroecuatorianos o montubios, se designará como séptimo consejero o consejera al candidato o candidata de los pueblos y nacionalidades indígenas, afroecuatorianos o montubios, que haya obtenido la mayor votación, [...]".

Lo extraño de la disposición citada es que no se menciona explícitamente la fórmula de decisión, que se supone que es la de mayoría 
relativa de los tres candidatos de la lista de mujeres y hombres, y de uno de la tercera lista. También es llamativo que, puede producirse el caso de que el candidato ganador de la tercera lista no sea electo, si entre los elegidos de las dos primeras listas no hay uno de origen indígena o afroecuatoriano y el primero de la lista es un ecuatoriano residente en el extranjero que no pertenece a esos grupos étnicos. En realidad, no debería permitirse que existan candidaturas de los pueblos y nacionalidades indígenas y afroecuatorianos en las otras listas, si ya hay una reservada para ellos (Barrionuevo, 2019, pp. $33-47)$.

Las reglas de elección del CPCCS descritas fueron aplicadas por primera vez en las elecciones de marzo de 2019. En este proceso ya se dieron varias irregularidades, como la decisión del CNE de dividir ilegalmente las tres listas en tres papeletas separadas; la falta de reglas para el conteo de los votos nulos en un sistema de voto personalizado; y, la calificación de candidatos que no cumplían los requisitos.

\section{Sistemas electorales locales}

Las regulaciones sobre los sistemas electorales locales están contenidas en la Constitución (arts. 251-255), en la LOEOP (arts. 120, 152-160 y162-164) y en el Código Orgánico de Organización Territorial, Autonomía y Descentralización -COOTAD- (arts. 33, 36, 38, 43-46, 49, 51, $56,59,61,66,69,71$ y 317$)$. Las elecciones locales se realizan cada cuatro años y no deben coincidir con las elecciones generales (art. 90 LOEOP). Solo la elección del CPCCS es simultánea con las locales (art. 207.3 CR).

Sistemas electorales para los órganos colegiados de los GAD

La LOEOP establece una serie de reglas generales -son las mismas que para la Asamblea Nacional- aplicables a la elección de los órganos colegiados de los GAD (consejos regionales, concejos cantonales, concejos metropolitanos y JPR). Estas se refieren al tipo de candidatura (lista cerrada y bloqueada, art. 120), el procedimiento de votación (voto único por lista, art. 160), la fórmula de decisión (proporcional) y el método de adjudicación de escaños (Webster, art. 164). Las circunscripciones corresponden a cada nivel de gobierno: para los consejos regionales, el distrito electoral es la región, con 
zonas urbanas y rurales; para los concejos municipales, el cantón, con zonas urbanas y rurales; y, para las JPR, el distrito es el territorio de la parroquia rural respectiva. A continuación, solo se describirán las características particulares de las reglas electorales de cada GAD (véase tabla 5).

Tabla 5: Sistema electoral de los órganos colegiados de los GAD

\begin{tabular}{|c|c|c|c|c|c|c|}
\hline & \multirow[b]{2}{*}{$\begin{array}{l}\text { Candida- } \\
\text { tura }\end{array}$} & \multirow{2}{*}{$\begin{array}{l}\text { Procedi- } \\
\text { miento. } \\
\text { votación }\end{array}$} & \multicolumn{2}{|c|}{ Circunscripción } & \multirow{2}{*}{$\begin{array}{l}\text { Fór- } \\
\text { mula } \\
\text { de de- } \\
\text { cisión }\end{array}$} & \multirow{2}{*}{$\begin{array}{l}\text { Méto- } \\
\text { do de } \\
\text { adjud. }\end{array}$} \\
\hline & & & Tipo & $\begin{array}{c}\text { Tamaño según } \\
\text { población }\end{array}$ & & \\
\hline $\begin{array}{l}\text { Consejeros } \\
\text { regionales }\end{array}$ & $\begin{array}{c}\text { Lista } \\
\text { cerrada y } \\
\text { bloquea- } \\
\mathrm{da}^{\mathrm{a}}\end{array}$ & $\begin{array}{c}\text { Voto } \\
\text { único } \\
\text { por lista }\end{array}$ & $\begin{array}{l}\text { Urbana y } \\
\text { rural de la } \\
\text { región }\end{array}$ & $\begin{array}{l}\text { - } 15 \text { (menos de } \\
1 \text { millón) } \\
\text { - } 19 \text { (más de } 1 \\
\text { millón) } \\
\text { - } 21 \text { más de } 2 \\
\text { millones) } \\
\text { - } 25 \text { (más de } 3 \\
\text { millones) } \\
\text { No mayores a } \\
7 \text { escaños }\end{array}$ & $\begin{array}{c}\text { Propor- } \\
\text { cional }\end{array}$ & Webster \\
\hline $\begin{array}{l}\text { Consejeros } \\
\text { provincia- } \\
\text { les }\end{array}$ & n.a. & n.a. & n.a. & n.a. & n.a. & n.a. \\
\hline $\begin{array}{l}\text { Concejales } \\
\text { distritales }\end{array}$ & $\begin{array}{c}\text { Lista } \\
\text { cerrada y } \\
\text { bloquea- } \\
\mathrm{da}^{\mathrm{a}}\end{array}$ & $\begin{array}{c}\text { Voto } \\
\text { único } \\
\text { por lista }\end{array}$ & $\begin{array}{c}\text { Urbana y } \\
\text { rural del } \\
\text { distrito me- } \\
\text { tropolitano }\end{array}$ & $\begin{array}{l}\text { - } 15 \text { (menos de } \\
1 \text { millón) } \\
\text { - } 19 \text { (más de } 1 \\
\text { millón) } \\
\text { - } 21 \text { (más de } 2 \\
\text { millones) } \\
\text { - } 25 \text { (más de } 3 \\
\text { millones) } \\
\text { No mayores a } \\
7 \text { escaños }\end{array}$ & $\begin{array}{l}\text { Propor- } \\
\text { cional }\end{array}$ & Webster \\
\hline
\end{tabular}




\begin{tabular}{|c|c|c|c|c|c|c|}
\hline $\begin{array}{l}\text { Concejales } \\
\text { cantonales }\end{array}$ & $\begin{array}{l}\text { Lista } \\
\text { cerrada y } \\
\text { bloquea- } \\
\text { da }^{\text {a }}\end{array}$ & $\begin{array}{c}\text { Voto } \\
\text { único } \\
\text { por lista }\end{array}$ & $\begin{array}{l}\text { Urbana y } \\
\text { rural del } \\
\text { cantón }\end{array}$ & $\begin{array}{l}\text { - } 5 \text { (menos de } \\
50 \text { mil) } \\
\text { - } 7 \text { (más de } 50 \\
\text { mil) } \\
\text { - } 9 \text { (más de } \\
100 \text { mil) } \\
\text { - } 11 \text { (más de } \\
200 \text { mil) } \\
\text { - } 13 \text { (más de } \\
300 \text { mil) } \\
\text { - } 15 \text { (más de } \\
400 \text { mil) } \\
\text { No mayores a } \\
7 \text { escaños. }\end{array}$ & $\begin{array}{c}\text { Propor- } \\
\text { cional }\end{array}$ & Webster \\
\hline $\begin{array}{c}\text { Vocales de } \\
\text { JPR }\end{array}$ & $\begin{array}{c}\text { Lista } \\
\text { cerrada y } \\
\text { bloquea- } \\
\text { da }^{\text {a }}\end{array}$ & $\begin{array}{c}\text { Voto } \\
\text { único } \\
\text { por lista }\end{array}$ & $\begin{array}{l}\text { Parroquial } \\
\text { rural }\end{array}$ & $\begin{array}{c}\text { - } 5 \text { (hasta } 150 \\
\text { mil) } \\
-7 \text { (más de } \\
150 \text { mil) }\end{array}$ & $\begin{array}{c}\text { Propor- } \\
\text { cional }\end{array}$ & Webster \\
\hline
\end{tabular}

Nota: a Las listas deben ser secuenciales y alternadas entre mujeres y hombres, $50 \%$ encabezadas por mujeres y $25 \%$ compuestas de jóvenes. La regla sobre el encabezamiento paritario se aplicará progresivamente: elecciones seccionales de 2023, el 30\% y, en las de 2027, el 50\%.

Fuente: Constitución 2008; LOEOP 2009, ref. 2020; COOTAD 2010.

Según el art. 152 de la LOEOP, el tamaño de los consejos regionales y los concejos metropolitanos puede tener entre 15 y 25 miembros, según su población, y se debe conformar obligatoriamente distritos urbanos y rurales en proporción a los habitantes. Además, se dispone que las circunscripciones mayores a 7 escaños se subdividan con los mismos criterios que los distritos para la Asamblea Nacional.

En cambio, los consejos provinciales no son electos popularmente, sino que se conforman por los alcaldes o concejales de los cantones que integran la provincia respectiva y por representantes de las parroquias rurales elegidos de entre los presidentes de las JPR (art. $252 \mathrm{CR}$ ). El COOTAD, en los arts. 43-46, regula a detalle la conformación de los GAD provinciales. Para la representación de los cantones se dispone que cada municipio de la provincia esté representado por el respectivo alcalde o, en el caso de no 
poder asistir, por el concejal principal que él designe (art. 44). El número de representantes de las parroquias rurales se determina según la población de la provincia, conforme a las siguientes reglas: (1) en las provincias de hasta 100 mil habitantes, tres; (2) en las de 100.001 hasta los 200 mil, cinco y (3) en las de más de 200.000, siete (art. 45.1). Para el proceso de selección, el CNE conforma un colegio electoral con todos los presidentes de las JPR para que, entre ellos, elijan a representantes de los diversos cantones, en lo posible (art. 46). Además, se dispone que solo duren en sus cargos como “consejeros provinciales" dos años (art. 45.2), sin posibilidad de reelección, a menos que, por el número de parroquias rurales, se tenga nuevamente que elegir al mismo representante (art. 46.2).

Los concejos cantonales pueden variar también su tamaño dependiendo de su población entre 5 y 15 concejales (art. 156 LOEOP). Además, es mandatorio que se creen circunscripciones urbanas y rurales en relación proporcional con la población (art. 157.1 LOEOP). Y, se dispone que los distritos entre 8 y 12 escaños se dividan en dos (art. 157.2 LOEOP); sin embargo, el Legislador no estableció qué sucede con los que tienen 13 o más escaños.

Hay que señalar que, en el caso de que se tenga que elegir a un solo consejero regional, concejal metropolitano o concejal cantonal, la regla de decisión será la mayoría relativa (art. 159 LOEOP).

Finalmente, el tamaño de las JPR depende asimismo de la población: (1) en las parroquias rurales hasta 50 mil habitantes, habrá cinco miembros y (2), en las que tengan más de 50 mil, siete (art. 158 LOEOP).

Sistemas electorales para los órganos ejecutivos de los GAD

Todos los GAD están encabezados por dos autoridades ejecutivas: los consejos regionales, por un gobernador regional y un vicegobernador regional (art. $251 \mathrm{CR}$; ); los consejos provinciales, por un prefecto y un viceprefecto (art. $252 \mathrm{CR}$ ); los concejos cantonales, por un alcalde y un vicealcalde (art. $253 \mathrm{CR}$ ); los concejos metropolitanos, por un alcalde metropolitano y un vicealcalde metropolitano (art. $254 \mathrm{CR}$; art. 91 COOTAD); y, las JPR, por un presidente y un vicepresidente (art. $255 \mathrm{CR}$; art. 66 COOTAD). El 
vicegobernador regional, el vicealcalde cantonal, el vicealcalde metropolitano, y los presidentes y vicepresidentes de las JPR no son electos popularmente.

Las reglas generales (véase tabla 7) para la elección de los ejecutivos locales son: (1) candidatura unipersonal, en el caso de los prefectos en binomio (art. 99.2 LOEOP); (2) voto único por el candidato o binomio (art. 119 LOEOP); (3) la circunscripción es la correspondiente a cada nivel de gobierno - para gobernadores regionales, la región; para prefectos y viceprefectos, la provincia; para alcaldes municipales, el cantón; y, para alcaldes metropolitanos, el distrito metropolitano correspondiente- (arts. 153-155 LOEOP); y, la fórmula decisoria es la mayoría relativa (arts. 153155 y $162-163$ LOEOP).

Tabla 6: Sistema electorales de los ejecutivos de los GAD

\begin{tabular}{|c|c|c|c|c|}
\hline $\begin{array}{c}\text { Gobernador } \\
\text { regional }\end{array}$ & Unipersonal & Voto único & Regional & $\begin{array}{c}\text { Mayoría } \\
\text { relativa votación }\end{array}$ \\
\hline $\begin{array}{c}\text { Prefecto } \\
\text { provincial }\end{array}$ & Unipersonal & Voto único & Circunscripción & $\begin{array}{c}\text { Fórmula de } \\
\text { decisión }\end{array}$ \\
\hline Alcalde distrital & Unipersonal & Voto único & $\begin{array}{c}\text { Distrito } \\
\text { metropolitano }\end{array}$ & $\begin{array}{c}\text { Mayoría } \\
\text { relativa } \\
\text { relativaráa }\end{array}$ \\
\hline $\begin{array}{c}\text { Alcalde } \\
\text { municipal }\end{array}$ & Unipersonal & Voto único & Cantón & $\begin{array}{c}\text { Mayoría } \\
\text { relativa }\end{array}$ \\
\hline Presidente JPR & n. a. & n. a. & n. a. & n. a. \\
\hline
\end{tabular}

Fuente: Constitución 2008; LOEOP 2009, ref. 2020; COOTAD 2010.

Las segundas autoridades de los ejecutivos regionales, cantonales y metropolitanos (el vicegobernador, vicealcalde cantonal y vicealcalde metropolitano, respectivamente) son electos por sus correspondientes cuerpos colegiados de entre sus miembros (arts. 38, 61 y 91 COOTAD); y, en esta elección, se debe respetar obligatoriamente el principio de paridad. Es decir, si la primera autoridad ejecutiva local es hombre, la segunda debe ser necesariamente una mujer y viceversa (art. 317 COOTAD). ${ }^{7}$

7 Véase las Normas Reformatorias, art. 167, letra f, de las reformas de 2020. 
Como ya se mencionó, los presidentes y vicepresidentes de las JPR no son seleccionados en elecciones directas, sino que se designa como presidente al candidato más votado de la lista $\mathrm{y}$, como vicepresidente, al segundo con la mayor cantidad de votos (art. $255 \mathrm{CR}$; art. 66 COOTAD). Sin embargo, en la reforma de febrero de 2020, el Legislador omitió cambiar esta regla, pues ya no hay más votados - esto era posible con listas abiertas y voto personalizado-. Ahora la lista es cerrada y bloqueada. Por tanto, aquí hay una laguna normativa que debe ser llenada rápidamente por la Asamblea Nacional para las elecciones locales de 2023.

\section{Balance de la reforma electoral de febrero de 2020}

La reforma a la LOEOP de 2020 será evaluada únicamente en sus posibles efectos mecánicos inmediatos sobre la realización de los principios constitucionales que deben inspirar los sistemas electorales que diseñe el Legislador (arts. 65 y 116). El incumplimiento de estos principios conlleva problemas en la representación política con respecto a la relación entre habitantes y escaños (sobre y subrepresentación territorial), al reparto justo de escaños según la fuerza electoral de cada organización política (desproporcionalidad) y a la participación política de las mujeres en los cargos de elección popular (desigualdad política de género).

\section{Criterios constitucionales de evaluación de la reforma electoral}

El art. 116 de la Constitución consagra por lo menos tres principios que deben guiar la legislación electoral: (1) igualdad del voto, (2) proporcionalidad y (3) paridad entre hombres y mujeres. La participación de las mujeres en la vida pública está reforzada por el mandato constitucional del art. 65.1: "El Estado promoverá la representación paritaria de mujeres y hombres en los cargos de nominación o designación de la función pública, en sus instancias de dirección y decisión, y en los partidos y movimientos políticos. [...]."

Con fundamento en estos principios constitucionales, a continuación, se hará un evaluación y crítica a la reforma a la LOEOP de 2020. 


\section{Principio de igualdad del voto en los sistemas electorales}

La fórmula de batalla por el acceso a la participación política se resumió en el principio: una persona, un voto y de igual valor. Históricamente esto no siempre fue así (Pérez Royo, 2014, p. 489). Las personas fueron excluidas de sus derechos políticos por su capacidad económica (voto censitario), su sexo (exclusión de las mujeres) o por su educación (exclusión de los analfabetos). Otra forma de limitar el derecho al voto fue dando un distinto valor o más votos a ciertas personas o grupos, como sucedió en Bélgica (hasta 1919), en que se concedía más números de votos (voto plural), según la cantidad de tierra. Todas estas barreras han desaparecido y la Constitución de 2008, en el art. 62, garantiza el derecho al sufragio activo para todas las personas, sin importar su condición social, su sexo o formación académica, desde los 16 años $^{8}$, y cada voto tiene el mismo valor.

Ahora, el peligro para el principio de igualdad del voto proviene del diseño y tamaño de los distritos electorales en relación con la densidad poblacional (Kelsen, 2005, p. 437-438). Nohlen (2000, p. 168) considera que una de las cuestiones fundamentales en el diseño de las circunscripciones electorales es saber si subyace una clave de la representación; es decir, si en las diversas circunscripciones electorales existe una relación simétrica entre el número de habitantes o electores y los escaños a repartirse. Una desviación relevante en esta relación se denomina malapportionment, que significa mal reparto. Esta distorsión afecta a la igualdad del voto en las distintas circunscripciones; ya que, en los distritos sobrerepresentados, el voto vale más y, en las zonas subrepresentadas, el voto vale menos.

En Ecuador se produce este mal reparto. Por ejemplo - para tomar los extremos-, en las elecciones generales de 2017, en la provincia de Galápagos, 20.206 electores eligieron dos legisladores; mientras que, en Guayas, 3.073.27, veinte (CNE, 2017). Es decir que la relación escañoelector es, en la Galápagos, uno por cada 10.103 electores y, en Guayas, uno por cada 153.664. Por tanto, el voto de un ciudadano en Galápagos vale 15,2 veces más que uno que vive en el Guayas. Y, la consecuencia de este sesgo

8 El sufragio universal para los varones fue reconocido por la Constitución de 1861; el voto de mujer, por la de 1929; el voto de los analfabetos, por la de 1979; y, el voto desde los 16 años, por la de 2008 (Grijalva, 1998). 
es que las provincias más pobladas (Guayas, Pichincha y Manabí) están subrepresentadas en comparación con las que tienen un menor número de habitantes (Galápagos, Pastaza y Zamora Chinchipe).

La reforma de 2020 no aborda este problema. Más bien el Constituyente y el Legislador han tendido a distorsionar la relación escaño-población o elector en cada circunscripción mediante los siguientes mecanismos: (1) establecimiento de la provincia como unidad electoral básica (art. $118 \mathrm{CR}$ ), a pesar de la diversa densidad poblacional; (2) la asignación automática de escaños -en este caso dos- a las provincias, independientemente del número de habitantes -este el principal problema- (art. 118 CR); (3) la creación de circunscripciones urbanas y rurales para la elección de los consejos regionales, concejos cantonales y concejos metropolitanos (arts. 251 y $253 \mathrm{CR}$; arts. 33.2, 56 y 86.2 COOTAD); y, además, (4) la subdivisión de las circunscripciones provinciales, distritales, regionales, cantonales y metropolitanas mayores a siete escaños (arts. 150, núm. 2, 152.3 y 157.2 LOEOP). El resultado: un cuadro muy fragmentado que tiende a favorecer los intereses locales y de pequeños grupos, y en el que es muy difícil mantener el equilibrio poblaciónrepresentación. En estas múltiples divisiones y subdivisiones sufre el principio de igualdad del voto: hay lugares en el territorio del país en los que el peso del voto de unos ciudadanos es mayor que en otros sitios.

Por lo menos, el Legislador, en la reforma de 2020, hubiese podido contribuir a mejorar las condiciones de igualdad del valor del voto si hubiese derogado los artículos que exigen inconstitucionalmente la subdivisión de las circunscripciones mayores a siete escaños.

Por otra parte, la asignación automática de dos escaños de asambleístas por provincia está establecida constitucionalmente (art. 118, núm. 2), y el objetivo de la norma es asegurar la representación de zonas periféricas del país, que históricamente han sido marginadas por el bicentralismo de Quito y Guayaquil. Por tanto, la solución a este sesgo de la representación política (provincias más pobladas con menos representación y provincias menos pobladas con más representación), no es fácil de resolver. Tratar de construir artificialmente circunscripciones que guarden una relación simétrica entre electorado y escaños es muy complicado en Ecuador, debido a la alta 
concentración de población en las zonas urbanas de las grandes ciudades. Para encontrar una solución habría que repensar si la provincia debe seguir siendo la unidad territorial electoral básica (Ortiz, 2016, p. 23).

\section{Principio de proporcionalidad en los sistemas electorales}

En los sistemas electorales ecuatorianos a nivel nacional y local aún queda mucho por hacer en cuanto a la justa relación entre votos y escaños; pero, el Legislador ha hecho muy poco. La contribución de la reforma 2020 fue cambiar el método de adjudicación de escaños D’Hondt por Webster para todas las elecciones pluripersonales (art. 164 LOEOP). Sin embargo, decidió mantener las reglas de subdivisión de las circunscripciones que prohíben los distritos mayores a siete escaños. Esta fragmentación desmedida del territorio electoral provoca que casi todas las circunscripciones tengan una baja magnitud y, en consecuencia, que el efecto global del sistema electoral de la Asamblea Nacional, consejos regionales, concejos cantonales y concejos metropolitanos sea más bien mayoritario, y no proporcional (Ortiz, 2020, p. 427).

En el caso ecuatoriano, la magnitud de la circunscripción es el elemento más decisivo para determinar el grado de proporcionalidaddesproporcionalidad (votos-escaños) del sistema electoral. Es fácil entender que, si se tiene que distribuir solamente cuatro escaños entre diez partidos, nunca habrá reparto proporcional, ya que a lo mucho alcanzará para cuatro organizaciones políticas y quedarán siempre excluidos seis partidos, independientemente del método de asignación de escaños -D'Hondt vs. Webster- (Ramírez, 2016, pp. 68-70). 
Tabla 7: Desproporcionalidad en las 31 circunscripciones del territorio ecuatoriano para la elección de la Asamblea Nacional

\begin{tabular}{|c|c|c|c|}
\hline \multirow{2}{*}{$\begin{array}{c}\text { Tamaño } \\
\text { circunscripción }\end{array}$} & \multirow{2}{*}{$\begin{array}{c}\text { Número } \\
\text { circunscripciones }\end{array}$} & \multicolumn{2}{|c|}{ Promedio IG } \\
\cline { 3 - 4 } & 1 & $\mathbf{2 0 1 3}$ & $\mathbf{2 0 1 7}$ \\
\hline 6 escaños & 8 & 22,0 & 17,7 \\
\hline 5 escaños & 10 & 22,0 & 18,4 \\
\hline 4 escaños & 6 & 28,2 & 23,3 \\
\hline 3 escaños & 6 & 29,4 & 31,4 \\
\hline 2 escaños & & $\begin{array}{c}\text { Promedio: } \\
\text { Total: } 31\end{array}$ & $\mathbf{2 4 , 9}$ \\
\hline
\end{tabular}

Nota: Elaboración propia.

Como ejemplo de lo que sucede con la proporcionalidad -mejor dicho, con la desproporcionalidad-, la tabla 7 muestra la desviación entre los porcentajes de votos y el porcentaje de escaños en los 31 distritos electorales del territorio nacional para la elección de 116 legisladores de los 137 -los 21 escaños restantes son los 15 asambleístas nacionales y los 6 legisladores de las tres circunscripciones del exterior-. El promedio de todos los distritos es de apenas 3,7 escaños y, en casi todos los grupos de circunscripciones, la desproporción supera los 20 puntos en el índice de Gallagher-IG- (Gallagher, 1991), hecho que prácticamente tiene efectos mayoritarios, es decir, que solo dos partidos en promedio - con D'Hondt- tenían la opción de obtener escaños. La diferencia de 2,4 puntos entre 2013 y 2017 se explica por la pérdida de fuerza electoral del movimiento político más grande (Alianza PAIS) en las elecciones de 2017. Con la introducción de Webster por la reforma de 2020, mejorará parcialmente la proporcionalidad en algunas circunscripciones y, en las elecciones de 2021, seguramente tres organizaciones políticas -en promedio- tendrán posibilidades de participar en el reparto de puestos en la Asamblea Nacional.

También puede considerarse un pequeño aporte a la proporcionalidad la introducción de la lista cerrada y bloqueada; pues, las listas abiertas permitían una dispersión del voto que hacía imposible establecer una 
adecuada conexión entre la fuerza electoral de una organización política y su representación parlamentaria.

No obstante, el Legislador no afrontó el problema real de la proporcionalidad: la regla que obliga a subdividir las circunscripciones provinciales, distritales, regionales, cantonales y metropolitanas mayores a siete escaños. Si se quería una representación más justa, era necesario derogar los arts. 150, núm. 2, inc. 2, 152.3 y 157.2 de la LOEOP. Aunque sí se intentó por lo menos eliminar el párrafo segundo del núm. 2 del art. 150 LOEOP -mediante el veto presidencial-, los grupos políticos que pensaban que se podían aprovechar de la reducida magnitud del distrito (PSC y $\mathrm{RC}^{9}$ ) se opusieron a la reforma. No es raro que la mayoría de los políticos prefieran sus intereses a la Constitución.

En el futuro, la tarea de una reforma electoral integral sería diseñar la manera de cómo cumplir con el mandato de proporcionalidad en los sistemas electorales nacionales y locales. Parte de la solución sería, obviamente, eliminar la subdivisión de distritos e incluir escaños compensatorios para las organizaciones políticas que han sido perjudicadas en el reparto de escaños (Ramírez, 2016, pp. 91-95). Pero esta propuesta tendría su precio: aumentar el tamaño de los cuerpos colegiados, costo que no todos estamos dispuestos a asumir.

\section{El principio de paridad de género en los sistemas electorales}

En el objetivo de mejorar las oportunidades electorales de las mujeres, el Legislador, en la reforma de 2020, hizo su mejor trabajo: (1) paridad total en los candidatos que se presentan en binomios (presidente de la República y prefectos); (2) paridad estricta en la elección indirecta de las segundas autoridades ejecutivas de los concejos cantonales y concejos metropolitanos -se olvidaron de los presidentes y vicepresidentes de las JPR-; y, (3) -la medida más potente- paridad obligatoria en el encabezamiento de listas en las circunscripciones pluripersonales (art. 99 y 167.4 LOEOP; art. 317 COOTAD). Estas reglas, con seguridad, se traducirán en una presencia más

9 "César Solórzano (PSP), vicepresidente de la Asamblea Nacional, cree que el PSC y el correísmo están a favor de que continúen las circunscripciones porque esperan tener una gran mayoría de asambleístas en las próximas elecciones." (Elcomercio.com, 03/02/20. En: https://www.elcomercio.com/ actualidad/grupos-politicos-escanos-circunscripciones-politica.html). 
efectiva de las mujeres en la política nacional y local.

Una imagen de las trabas que tuvieron que superar las mujeres para mejorar su presencia en la política nacional nos puede brindar la composición histórica del parlamento ecuatoriano. La tabla 8 muestra cómo las tres primeras décadas de vida democrática estuvieron dominadas por hombres. En el primer Congreso Nacional de 1979, de los 69 legisladores, ninguno era mujer. Hasta antes de la ley de cuotas de 1998, la presencia de mujeres legisladoras no alcanzaba el 10\%. Con la nueva de ley de cuotas de 2000, las mujeres lograron mayor presencia, pero no llegaban al 30\% del total del cuerpo legislativo. Finalmente, las elecciones con listas paritarias, secuenciales y alternadas contribuyeron a que las mujeres alcancen hasta casi el 40\% de representación en las asambleas de 2013 y 2017 (Torres, 2016, pp. 129-132; Sosa, 2020, pp. 368-370).

Tabla 8: Evolución de la representación legislativa de las mujeres 1979-2013

\begin{tabular}{|c|c|c|c|c|c|}
\hline & $\begin{array}{c}\text { Total } \\
\text { legisladores }\end{array}$ & $\begin{array}{c}\text { Mujeres } \\
\text { en el } \\
\text { parlamento }\end{array}$ & Cuota & $\begin{array}{c}\text { \% de } \\
\text { mujeres }\end{array}$ & $\begin{array}{c}\text { \% de } \\
\text { crecimiento }\end{array}$ \\
\hline $\mathbf{1 9 7 9}$ & 69 & 0 & 0 & 0,0 & 0,0 \\
\hline $\mathbf{1 9 8 4}$ & 71 & 3 & 0 & 4,2 & 4,2 \\
\hline $\mathbf{1 9 8 6}$ & 71 & 1 & 0 & 1,4 & $-2,8$ \\
\hline $\mathbf{1 9 8 8}$ & 71 & 5 & 0 & 7,0 & 5,6 \\
\hline $\mathbf{1 9 9 0}$ & 72 & 5 & 0 & 6,9 & $-0,1$ \\
\hline $\mathbf{1 9 9 2}$ & 77 & 4 & 0 & 5,2 & $-1,7$ \\
\hline $\mathbf{1 9 9 4}$ & 72 & 7 & 0 & 9,7 & 4,5 \\
\hline $\mathbf{1 9 9 6}$ & 82 & 5 & 0 & 6,1 & $-3,6$ \\
\hline $\mathbf{1 9 9 8}$ & 121 & 16 & $20 \%$ & 13,2 & 7,1 \\
\hline $\mathbf{2 0 0 2}$ & 100 & 17 & $35 \%$ & 17,0 & 3, \\
\hline $\mathbf{2 0 0 6}$ & 100 & 25 & $45 \%$ & 25,0 & 8,0 \\
\hline $\mathbf{2 0 0 9}$ & 124 & 40 & Paridad & 32,3 & 7,3 \\
\hline $\mathbf{2 0 1 3}$ & 137 & 53 & Paridad & 38,7 & 6,4 \\
\hline $\mathbf{2 0 1 7}$ & 137 & 52 & Paridad & 38,0 & $-0,7$ \\
\hline
\end{tabular}


Fuente: tomado de Torres, 2016, p. 130, actualizado.

El obstáculo más importante que no permitía a las mujeres efectivizar su participación en las candidaturas en una real representación parlamentaria era el encabezamiento de listas (Andrade 2012; Goyes 2013; Torres, 2016). Las organizaciones políticas -normalmente dominadas por hombres-tienden a poner a las mujeres en los segundos lugares de las listas. Más o menos el $80 \%$ del total de listas en las elecciones nacionales $(2017: 82,4 \%$ ) y locales (2019: $\left.78,8 \%^{10}\right)$ tenían en primer lugar a un candidato hombre. Este sesgo en las listas desfavorecía doblemente a las mujeres: (1) perdían número de candidatas en las circunscripciones impares, pues empezaban con hombres y terminaban con hombres; y, (2) disminuían sus oportunidades de ser electas, ya que el elector se orienta regularmente por el candidato ubicado en el primer lugar para emitir su voto. A esta situación hay que agregar el hecho de que, en las candidaturas unipersonales, dominaban claramente los hombres.

\section{Tabla 9: Relación de paridad candidatos y electos en las elecciones nacionales 2017 y locales 2019}

\begin{tabular}{|c|c|c|c|c|c|c|c|c|c|}
\hline & \multicolumn{4}{|c|}{ Candidaturas } & \multicolumn{4}{|c|}{ Electos } & \multirow{3}{*}{$\begin{array}{c}\text { En- } \\
\text { cab. } \\
\text { de } \\
\text { lista } \\
\text { mu- } \\
\text { jeres } \\
\% \%\end{array}$} \\
\hline & \multicolumn{2}{|c|}{ Hombres } & \multicolumn{2}{|c|}{ Mujeres } & \multicolumn{2}{|c|}{ Hombres } & \multicolumn{2}{|c|}{ Mujeres } & \\
\hline & Núm. & $\%$ & Núm. & $\%$ & Núm. & $\%$ & Núm. & $\%$ & \\
\hline $\begin{array}{l}\text { Presidente } \\
\text { República }\end{array}$ & 7 & 87,5 & 1 & 12,5 & 1 & 100,0 & 0 & 0,0 & 12,5 \\
\hline $\begin{array}{c}\text { Asamblea } \\
\text { Nacional }\end{array}$ & 948 & 53,5 & 824 & 46,5 & 85 & 62,0 & 52 & 38,0 & 17,6 \\
\hline Prefectos & 183 & 82,1 & 40 & 17,9 & 19 & 82,6 & 4 & 17,4 & 17,9 \\
\hline Alcaldes & 1.607 & 85,7 & 268 & 14,3 & 203 & 91,9 & 18 & 8,1 & 14,3 \\
\hline $\begin{array}{l}\text { Concejos } \\
\text { cantonales }\end{array}$ & 6.826 & 54,7 & 5.653 & 45,3 & 901 & 68,9 & 406 & 31,1 & 23,3 \\
\hline JPR & 15.102 & 56,1 & 11.833 & 43,9 & 2.988 & 73,0 & 1.106 & 27,0 & 19,7 \\
\hline
\end{tabular}

10 En las candidaturas para concejales urbanos, las mujeres solo representaban el $24,1 \%$; para concejales rurales, el 22,4\%; y, para vocales de las JPR, el 19,7\%. 
Fuente: CNE; Instituto de la Democracia.

La tabla 9 muestra las tendencias descritas anteriormente. En las elecciones pluripersonales, las mujeres, a pesar de las listas paritarias, tienen menos candidatos que los hombres (Asamblea Nacional: 46,5\%; concejos cantonales: el 45,3\%; JPR: 43,9\%); y, esa menor cantidad de candidaturas se reduce significativamente en cuanto al porcentaje de electas, sobre todo en las JPR (Asamblea Nacional: menos 8,5 puntos porcentuales; consejos cantonales: menos 14,2; JPR: menos 16,9). En las elecciones unipersonales, la situación es aún más dramática: Las candidaturas de las mujeres no llegan ni al $20 \%$ del total (presidente de la República: 12,5\%; prefectos: 17,9\%; alcaldes: $14,3 \%$ ); y, las electas también se reducen: nunca una mujer ha sido electa presidente de la República; y, en las elecciones locales 2019, de los 23 prefectos provinciales del país solo cuatro eran mujeres $(17,4 \%)$, y de los 221 alcaldes, solo $18(8,1 \%)$.

Para contrarrestar estos efectos negativos en la representación efectiva de las mujeres en los cargos de elección popular, la reforma de 2020 estableció las siguientes reglas en los arts. 99 y 167.4 LOEOP y 317 COOTAD:

1) Todas las candidaturas que se presentan en binomio (presidente la República y prefectos) estarán obligatoriamente conformados por una mujer y un hombre.

2) El $50 \%$ de las candidaturas para las prefecturas que inscriba una organización política en las 23 provincias estarán encabezadas por mujeres.

3) El $50 \%$ de las candidaturas para las alcaldías que inscriba una organización política en cada provincia serán de mujeres.

4) En la elección indirecta de la vicegobernación, vicealcaldía y vicealcaldía metropolitana por los consejos regionales, concejos cantonales y concejos metropolitanos se respetará obligatoriamente la paridad: si el gobernador, alcalde o alcalde metropolitano es un hombre, la vicegobernadora, vicealcaldesa o vicealcaldesa metropolitana será necesariamente una mujer, y viceversa (no hay regulación sobre los presidentes y vicepresidentes de las JPR). 
5) Una de las dos listas de asambleístas nacionales o de parlamentarios que presente una organización política debe estar encabezadas por una mujer.

6) El 50\% del total de listas que presente una organización política para asambleístas provinciales (21 circunscripciones) y del exterior (3 distritos) deberán estar encabezadas por mujeres.

7) El $50 \%$ de listas que presente una organización política para asambleístas de distritos en cada provincia (Guayas: 4, Pichincha: 4 y Manabí: 2) tendrán que estar encabezadas por mujeres.

8) El 50\% de listas que presente una organización política para los concejos cantonales en cada provincia deberá estar encabezada por una mujer.

9) El 50\% de listas que presente una organización política para vocales de las juntas parroquiales rurales en cada cantón deberá estar encabezada por una mujer.

Estas medidas que aseguran la paridad horizontal (Benavides, 2019, pp. 155-156; Bareiro y Soto, 2019, p. 741) en las candidaturas de las mujeres serán aplicadas progresivamente: (1) Para el binomio presidencial, desde las elecciones de 2025; para prefectos y alcaldes, en 2023: 30\% y en 2027: 50\%; para asambleístas, en 2021: 15\% y en 2025: 50\%; para concejales cantonales y vocales de las JPR, en 2023: 30\% y en 2027: 50\% (Disposición Transitoria Tercera, LOEOP). Obviamente que estas regulaciones no carecen de dificultades, pues hay movimientos políticos locales que presentan una sola lista y no podrán cumplir con la paridad horizontal; y, como siempre, habrá organizaciones políticas que colocarán a las mujeres en la cabeza de lista en las circunscripciones que tengan menos oportunidades.

También pueden ser considerados como aportes positivos para la paridad de la reforma de 2020 la introducción de la lista cerrada y bloqueada (art. 120 LOEOP) y del método Webster (más proporcional que D’Hondt); ya que, por un lado, el estricto orden de paridad será respetado en cada lista $\mathrm{y}$, por otro, el reparto más proporcional ofrecerá mayores oportunidades a las mujeres de ser electas (Jones, Alles y Tchintian, 2012). Pero estos resultados también dependen de la distribución de votos en cada circunscripción. Lo 
que sí no colabora con la paridad es la subdivisión de las circunscripciones y su reducido tamaño (Archenti y Tula, 2007), aspecto que el legislador no quiso afrontar.

Para finalizar, solo un breve comentario sobre la inclusión intergeneracional que ordena el Legislador en la reforma de 2020. El núm. 8 del art. 99 de la LOEOP manda que, en todas las candidaturas para elecciones pluripersonales, para alcaldes y prefectos, las organizaciones políticas deberán incluir por lo menos el $25 \%$ de mujeres y hombres jóvenes. Para efectos de la ley, se consideran jóvenes las personas entre 18 y 29 años (Disposición General Novena, LOEOP). Aunque el objetivo puede ser loable, se debió limitar la participación obligatoria de los jóvenes a las elecciones locales, con el fin de que adquieran experiencia en los asuntos públicos y puedan, después, participar en la política nacional con mayor preparación; pues, los asuntos nacionales son muy complejos.

\section{Conclusiones}

La reforma de febrero de 2020, de manera global, incluye avances importantes para mejorar la participación política de las mujeres (representación de género), pero no soluciona los problemas de la representación territorial (sobre y subrepresentación) y de la representación justa de las fuerzas políticas en el país (desproporcionalidad).

(1) Las reglas que obligan a la paridad en ejecutivos nacionales y locales y la paridad horizontal en listas para órganos colegiados son el aporte más importante de la reforma de 2020. Estas disposiciones seguramente mejorarán la representación efectiva de las mujeres en los puestos de elección popular.

(2) La introducción de la lista cerrada y bloqueada también puede ser evaluada positivamente, ya que permite un reparto más transparente de escaños con relación al porcentaje de votos de cada organización política, y mejora las oportunidades de las mujeres de lograr una mejor representación en los cuerpos colegiados a nivel nacional y local.

(3) El consecuente paso del voto personalizado al voto de lista también 
ofrece la oportunidad de que las preferencias electorales de los ciudadanos se expresen de manera estructurada y no se fomente el personalismo y, además, tiende a favorecer a las oportunidades electorales de las mujeres.

(4) El reemplazo de D'Hondt por Webster es ambivalente; por un lado, aumenta la proporcionalidad en el gran número de circunscripciones pequeñas -que también favorece a la representación de género-, pero no resuelve la distribución justa de escaños parlamentarios a nivel nacional; pero, por otro, alienta la fragmentación del sistema de partidos a nivel parlamentario, ya que es muy probable que aumente el número de partidos en la Asamblea Nacional, hecho que hará más difícil las relaciones ejecutivo-legislativo.

(5) La inclusión de cuotas para los jóvenes puede ser evaluada positivamente, pero debió limitarse a la política local, sobre todo a las juntas parroquiales rurales y a los concejos cantonales, pero no se debió exigir para las candidaturas a la Asamblea Nacional. Al poder legislativo nacional deben llegar los políticos con mayor experiencia que ya tienen un recorrido exitoso en los gobiernos locales.

(6) Los grandes temas pendientes de la reforma de 2020 son las circunscripciones y el modelo global de representación a nivel nacional y local. Los arts. 150, 152 y 157 de la LOEOP -que debieron cambiarse para atenuar el efecto desproporcional e inconstitucional de las circunscripciones pequeñaspermanecieron por intereses políticos de las agrupaciones partidarias que esperan favorecerse en las próximas elecciones generales y locales. Tampoco se ha planteado como compensar la sobre y subrepresentación en las distintas provincias y sus efectos negativos en el valor del voto de cada ciudadano.

(7) Finalmente, el Legislador debería resolver el vació que causó la reforma de 2020 sobre la designación de los presidentes y vicepresidentes de las JPR. Hay que hacer rápidamente una reforma y determinar que, esas autoridades deberían ser los dos primeros candidatos de la lista más votada. De paso, sería aconsejable revisar el sistema electoral del CPCCS y hacerlo más sencillo y transparente.

Como este estudio solo incluye una evaluación preliminar de las reformas electorales de febrero de 2020, es deseable que, con los datos 
electorales de las próximas elecciones generales y locales, se realicen nuevas investigaciones sobre los efectos de los sistemas electorales ecuatorianos sobre la igualdad del voto, la proporcionalidad y la paridad, y otros temas de relevancia para la democracia ecuatoriana. 


\section{Referencias}

Archenti, N. y Tula, M. (2007). "Cuotas de género y tipo de lista en América Latina”. Opinião Pública, 13(1), 185-218. https://doi.org/10.1590/ S0104-62762007000100007

Andrade, J. (2012). "Sistema electoral ecuatoriano y participación de las mujeres en las elecciones legislativas 2006 y 2009” (Tesis de maestría). Recuperado de http://repositorio.flacsoandes.edu.ec/bitstream/10469/5314/2/ TFLACSO-2012JAAA.pdf

Bareiro, L. y Soto, L. (2019). "Representación política de las mujeres. En D. Nohlen, L. Valdés y D. Zovatto”, Derecho electoral latinoamericano (pp. 728-756). México: FCE.

Barrionuevo, L. (2019). "Problemas constitucionales del sistema electoral del Consejo de Participación Ciudadana y Control Social". Tesis de grado. Quito: UDLA".

Benavides, T. (2019). "El efecto de los mecanismos de paridad vertical y horizontal en la representación política en Costa Rica: el caso de las elecciones legislativas de 2018". Derecho electoral, 27. https://www.tse. go.cr/revista/art/27/benavides_santos.pdf

Consejo Nacional Electoral (2019). Resultados electorales 2019. Quito: CNE.

Consejo Nacional Electoral (2017). Resultados electorales 2017. Quito: CNE.

Consejo Nacional Electoral (2014). Atlas electoral del Ecuador. Quito: CNE.

Duverger, M. (2001). "Influencia de los sistemas electorales en la vida política. En A. Batlle (Ed.)”, Diez textos básicos de ciencia política (pp. 37 76). Barcelona: Ariel.

Gallagher, M. (1991). "Proportionality, Desproportionality and Electoral Systems". Electoral Studies, 10(1), 33-51. 
Goyes, S. (2013). "Paridad, ¿un camino a la igualdad? Análisis de las elecciones 2013". Democracias, 1, 37-70.

Grijalva, A. (1998). Elecciones y representación política. Quito: Corporación Editora Nacional y UASB-Ecuador.

Jones, M, Alles, S. y Tchintian, C. (2012). "Cuotas de género, leyes electorales y elección de legisladoras en américa latina". Revista de Ciencia Política, 32(2), 331-357. https://dx.doi.org/10.4067/S0718090X2012000200001

Kelsen, H. (2002). Teoría General del Estado. Granada: Comares.

Lijphart, A. (1995). Sistemas electorales y sistemas de partidos. Madrid: Centro de Estudios Constitucionales.

Lijphart, A. (2000). Modelos de democracia. Barcelona: Ariel.

Nohlen, D. (2019). "Sistemas electorales parlamentarios y presidenciales". En D. Nohlen, L. Valdés y D. Zovatto, Derecho electoral latinoamericano (pp. 372-413). México: FCE.

Nohlen, D. (2000). "Circunscripciones electorales". En Diccionario electoral (t. I, pp. 165-169). San José: CAPEL.

Nohlen, D., Valdés, L. y Zovatto, D. (2019). Derecho electoral latinoamericano. México: FCE.

Ortiz, R. (2020). "Ingeniería electoral en Ecuador 1978-2020: de la transición a la democracia a la reinstitucionalización del sistema político". En Antología de la democracia ecuatoriana 1978-2020 (pp. 395-432). Quito: CNE e Instituto de la Democracia.

Ortiz, R. (2016). "Las singularidades del sistema electoral legislativo en Ecuador". En R. Ortiz (Ed.), Reforma electoral en Ecuador (pp. 7-37). Quito: UDLA.

Oyarte, R. (2019). Derecho constitucional. 3a. ed. Quito: CEP. 
Pérez Royo, J. (2014). Curso de Derecho Constitucional (14a. ed.; pp. 527-547) Madrid: Marcial Pons.

Ramírez, C. (2016). "El sistema electoral legislativo y el mandato constitucional de la proporcionalidad". En R. Ortiz (Ed.), Reforma electoral en Ecuador (pp. 39-96). Quito: UDLA.

Sosa, X. (2020). "La participación política de las mujeres en Ecuador 1998-2020". En Antología de la democracia ecuatoriana 1978-2020 (pp. 365-393). Quito: CNE e Instituto de la Democracia.

Schmidt, D. (2020). “¿Favorecen a las candidatas las listas abiertas o cerradas?: comparaciones entre Lima y las provincias en el Perú”. Apuntes, 47(86), 155-181. https://dx.doi.org/10.21678/apuntes.86.930

Torres, K. (2016). "Las barreras del sistema electoral legislativo a la paridad de género". En R. Ortiz (Ed.), Reforma electoral en Ecuador (pp. 97-162). Quito: UDLA. 